\title{
Three years on! Ohinewai Farmer Study Group. Pooling intellect and extracting information
}

\author{
N. BATEUP, M. CARLYON, J. COTMAN ${ }^{1}$, B. COTMAN, S. NELSON, B. O'REILLY, \\ M. \& P. BROWN and P. BUCKLEY \\ Ohinewai, Waikato \\ ${ }^{1} \mathrm{~J}$. Cotman, Settlers Road, RD1, Te Kauwhata \\ cotmanj@xtra.co.nz
}

\begin{abstract}
This paper documents the thinking and activities undertaken by a group of dairy farmers charting their own destiny with the assistance of science and industry knowledge. Examples are given of how the group has identified on-farm issues that have no single answer and how they have worked towards resolving these. Challenges for science working with farmers and farmer response to science are noted.
\end{abstract}

Keywords: clover, economics, environment, quality assurance, study group

\section{Introduction}

A group of dairy farmers in the North Waikato area was set up in 1995 to participate in a Technology for Business Growth/Ministry for the Environment funded trial, to determine if an interactive process involving farmers, science, and policy people would be an effective method of promoting sustainable land management inside the farm gate. The trial ran for 3 years and results have been documented and disseminated at various forums (Cotman 1996; Tarbotton et al. 1997). The challenge for the farmer members of the group was to maintain the momentum and use the forum for learning.

At a planning meeting in March 1998, we (farmers) decided to maintain the group because the method of pooling our intellectual knowledge and practical farming skills in a 'Study Group' process had been of major benefit. The core group has continued and moved forward, adding new members as circumstances warranted. The core group is $8-10$ farmers - this number fits into the average house sitting room. Trust is built up to a stage where farmers are quite happy to discuss their finances and share knowledge.

At the end of the original trial, we invited continued participation from both the science team and facilitation input from the Consulting Officer (CO) service. As a result of funding constraints on the science system, we were left to forge our own direction. This resulted in a positive outcome with the group taking control, and a re-evaluation of our group goals.
While the farmer members are also usually members of existing discussion groups run by the Dairy Board CO Service (now under Dexcel), we have found working together in a more intense and in-depth approach is of real value to our personal and business aspirations.

Today's group places emphasis on:

- Following issues in depth

We enjoy the challenge of working through an issue in-depth and over time. Unlike conventional discussion groups, we continue to test hypotheses and examine anecdotal evidence around some of our farm management practices until we can reach a consensus (see Case Study 1, below).

- Maintaining science contacts where necessary

As a group we have been able to access science input as required and we fully appreciate that input, but we are now more critical of the science and are more confident about directing science to deliver outcomes that we see as important (see Case Study 2).

- Valuing the facilitation of the Consulting Officer service

This has primarily been a result of the ongoing value that the $\mathrm{CO}$ (Bob O'Reilly) has placed on working alongside the farmers, stimulating discussion, raising questions of direction and recognising the value of the 'Study Group' process. We see this as one of the ways forward for the CO Service.

- Seeing value in the linkage to NZ Landcare Trust The group has seen the information sharing and linkage to Landcare Trust as useful. It allows us to demonstrate through the Landcare Trust network a farmer approach to the 'sustainable development' concept. This is one of our key founding principles.

- Being willing to become partners in funded projects We became an incorporated society with a workable constitution that allowed us to access funds when necessary. The process of becoming incorporated was not onerous and as well as providing for future funding, also provided the group with a formal statement of intent. This was seen as useful as it would provide new members with a clear idea of the group's aims. Being incorporated probably helps with applications to funding bodies such as AGMARDT (see under Thistle trial below). 


\section{Examples of what we have been involved in}

\section{Case study 1: What is the real problem?}

The value of clover in our pastures is well understood by the members. However, over the last 5 years, we had observed that clover levels in our pastures were declining to near zero. The problem appeared to be widespread in the Ohinewai-Waerenga area. Local problems affecting clover vigour have included; very dry summers with the potential for over-grazing, clover flea (Sminthurus viridis) and more recently, clover root weevil (Sitona lepidus). A case study approach was taken to monitor clover levels to see if any solutions could be found to the problem and whether high clover content could be re-established in clover-deficient swards.

All the members selected monitoring paddocks on their farms, in many instances these reflected past attempts to re-establish clover in their pastures. Methods had included direct drilling of new seed into Roundup-sprayed paddocks, full cultivation and oversowing into existing swards. Some members monitored clover content in long-established pasture. Descriptive information such as soil fertility and pugging history were collected. Pasture samples were collected and dissected for clover, grass, weeds and dead dry matter content on seven occasions over a 2-year period.

The results did not provide clear answers on how to maintain or enhance clover content. On a positive note, they did confirm the fact that re-sowing clover by one means or another, into a clover-deficient sward, will not, on its own, remedy the problem. Figure 1 shows that re-sowing on the Nelson farm successfully alleviated the clover problem for about a year but establishment ultimately failed. Clearly, some underlying factor(s) were working against clover retention. On the Bateup property, re-sowing clover was ineffective. The most consistent clover levels were observed in the unsown or un-renovated pasture of Brown (Figure 1) and on another member's property where clover content ranged from 10 to $20 \%$ of total dry matter.

Figure 1 Clover monitoring results from three of the properties in the Ohinewai Farmer Study Group

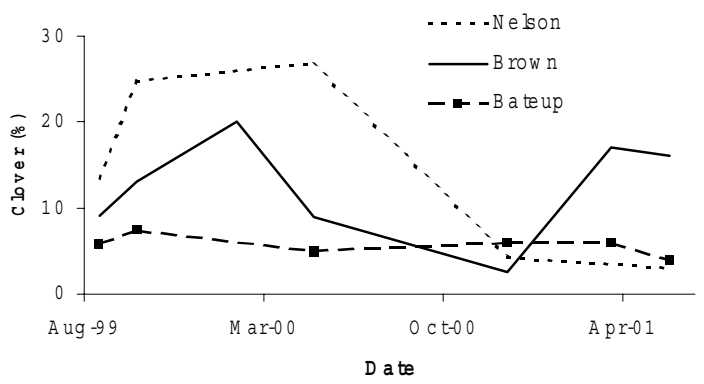

Why were the attempts to re-establish clover unsuccessful? All the paddocks tested had high soil fertility levels, no apparent history of pugging and in some cases were sprayed for clover flea control. On one farm where clover was consistently present, summer rainfall was reliable over the test period.

What conclusions can be derived from these results? It seems that:

- When contemplating pasture renovation, careful thought is required about what is going to change that will benefit clover survival.

- Clover content is probably a result of the balance between life and death and depends on which side of the equilibrium is dominant. The objective is to try to nudge it in favour of life. The differences between sites where clover is thriving vs. sites where it is struggling are apparently quite subtle and hard to detect.

- To date, the group has not been able to establish why clover content is consistently adequate on the two un-renovated sites, and low on the other sites. With the aid of scientists, they will continue to research this widespread problem and will investigate other issues such as soil compaction.

\section{Case study 2: Science and farmer conflict}

The dairy industry is aware of pressures from consumers who have views on the integrity of the food production systems including those on perceived animal welfare issues. Induction of calving is (rightly or wrongly) seen by many consumers as an area of concern. Our Group was asked to participate in some industry work in this area.

\section{Lessons}

As farmers, we initially took an approach that science would be able to provide us with the answers and thus we expected some in-depth science input. Peter and Margaret Brown's farm was chosen as the focus point. Separate meetings were held by the science support group and our farmer mentor group to document management practices that would be needed to lower the induction rate on this farm.

The science team appeared to be able to look at specific issues and deal with those separately. Our Group however, found it impossible to separate issues and rank them in importance, as our view is that all the management practices needed to be dealt with as a whole. In reality farmers face a complex set of issues that all interconnect and thus need to be dealt with in tandem. Scientists, if they are to interact inside the farm gate, must recognise this as a basis to start. In 
this trial, farmers' expectations were clearly different from those of the scientists involved and were clearly focused at the practical application of any work undertaken. The result was a mis-match of what practices we as farmers expected to learn from the sharing of knowledge, and what the scientists required from our participation in the work. We became aware therefore, of the need for setting out clear agendas and expectations at the outset of any proposed partnership with science.

\section{Other topics}

\section{On-farm quality assurance}

Development of a farmer friendly, self-assessment, on-farm quality assurance (QA) system. The group was invited to be part of the EQUAL project (a farmerled think tank of Agribusiness groups) to assess current QA systems and adapt them for farmer use. The current systems were seen as unworkable for the vast majority of farmers and the group process was applied to develop a template that would stimulate fellow farmer involvement in QA while still providing for some audit if required. This system has now been released by the dairy industry under the 'Market Focused' brand. The system concentrates on the key issues, e.g., environment, animal welfare, human health and safety. The process assisted in making the farmer think before the problem occurs. The farmer has to think of the question and the answer thus entailing thinking around the subject. The system differs from a checklist in that the outcome can be achieved by using Best Management Practices. It is tailored to meet individual issues with the key questions aligned to industry market issues. Going through the system also raises awareness, e.g., the wearing of safety glasses. Following the system is not time consuming.

\section{Thistle trial}

HortResearch isolated a fungus that appeared to attack and kill California thistle and approached our group to see if we wished to partner them in a series of on-farm trials. The group agreed to put both funds and time into this trial and also successfully attracted AGMARDT funding. It is a 2-year trial and, if successful, will add a cost-effective method of thistle control to the NZ farmer arsenal. This type of work is exciting as it would place us at the leading edge, should the treatment work.

\section{Twenty-month lactation trial}

Another advantage of working together and 'picking each others ideas' has been the ability to develop outside-the-square-thinking when confronting some of the management problems many farmers face. The group has initiated leading edge ideas. One such issue presently under consideration is that of finding an answer to the wastage of the young cows in our herds. A common problem is their low in-calf rates. A farmer in the group expressed the option of a 20-month lactation for these young animals. This will need science-backed trialling to test practical feasibility and cost effectiveness. The group now knows where to access information, has science networks and knows how to put together a funding application to enable this initiative to go ahead.

\section{Conclusions and challenges for the future}

\section{To science}

- recognise the value of on-farm ideas - put science around these

- recognise that farmers work with an integrated system and thus consider an integrated approach, i.e., see the "big" picture

- need to be fully accountable, i.e., reporting is needed on all projects including results and cost

- take the opportunity to increase knowledge by working alongside the top quartile of farmers.

\section{To fellow farmers}

- need to challenge yourselves and unlock what is in your heads

- need to develop the confidence to take responsibility for creating change

- do not be so accepting - you need to challenge science

- recognise the power of the group process

- need to identify projects beneficial to you - centre on your own concerns or needs and not what the scientists believe is invaluable.

To continue to move forward, we endorse the need to develop sound, long-term, sustainable systems that are backed by good science.

\section{REFERENCES}

Cotman, J. 1996. Farmer perspectives on sustainable farming. Proceedings of the New Zealand Grassland Association 57: 27-30.

Tarbotton, I.S.; Paine, M.S.; Wedderburn, M.E.; Carlyon, M. 1997. A method for improving farm practice: a case for pugging. Proceedings of the New Zealand Grassland Association 59: 79-85. 